\title{
A comparative study of sublingual versus oral misoprostol following oral mifepristone for second trimester termination of pregnancy
}

\author{
Ruchi Gupta*, Krishna Priya Banerjee, Reena Pant
}

Department of Obstetrics and Gynecology, S. M. S. Medical College, Jaipur, Rajasthan, India

Received: 07 November 2018

Accepted: 11 January 2019

*Correspondence:

Dr. Ruchi Gupta,

E-mail: ruchiguptamgm@gmail.com

Copyright: (C) the author(s), publisher and licensee Medip Academy. This is an open-access article distributed under the terms of the Creative Commons Attribution Non-Commercial License, which permits unrestricted non-commercial use, distribution, and reproduction in any medium, provided the original work is properly cited.

\begin{abstract}
Background: The objective of this study is to assess the effectualness and safety of sublingual versus oral misoprostol following oral mifepristone for second trimester termination of pregnancy.

Methods: This institution based contingent study was conducted on 220 women requesting for mid-trimester termination of pregnancy between 12-20 weeks with legal indication as per Govt. MTP act. After excluding the women as per exclusion criteria, they were randomly allocated into two groups (Group A Sublingual, Group B Oral), the women received $200 \mathrm{mg}$ oral mifepristone followed by sublingual or oral misoprostol $400 \mu \mathrm{g}$ three hourly for a maximum of 5 doses 48 hours later. The course of misoprostol was reiterated if women failed to abort in 24 hours.

Results: The mean induction-abortion interval of Group-A and Group -B was 4.02 \pm 1.39 hours and $6.44 \pm 1.79$ hours respectively. The mean dose of misoprostol in Group-A and Group-B was 680 $\pm 220.4 \mu \mathrm{g}$ and $1003.6 \pm 274.9 \mu \mathrm{g}$. Hence mean Induction-abortion interval and dose were shortened in Group-A as compare to Group-B ( $\mathrm{p}<0.05)$. There was $100 \%$ success rate noticed via both routes. Evacuation was done in 4 (3.64\%) women in Group-B as compare to only $1(0.91 \%)$ in Group-A . The acceptability was significantly more in Group-B (100\%) as compare Group-A (52.73\%), probably because of unpleasant taste of sublingual misoprostol. All side effects (Nausea, pain, headache, and diarrhea) were common in both the Groups, only fever was significantly more common in sublingual group as compare to oral group $(\mathrm{p}<0.05)$.

Conclusions: From present study authors conclude that, sublingual misoprostol when combined with mifepristone is effective for medical abortion in second trimester in terms of effectualness, endurability and success rate than oral route.
\end{abstract}

Keywords: Oral misoprostol, Second trimester abortion, Sublingual misoprostol

\section{INTRODUCTION}

Abortion is defined as desistance of pregnancy before 20 weeks of gestation or fetus weighing $<500 \mathrm{gm} .{ }^{1}$ In India, nearly 15 million abortions are estimated to be taking place each year, of those ten million risks their lives by approaching quacks or untrained abortion providers and almost 15,000 to 20,000 women die because of complication of unsafe abortion. $^{2}$ India, legalized termination of pregnancy on broad socio-medical ground through the MTP Act, in order to enable a woman to opt of an unwanted pregnancy in certain specific circumstances. The aim of the act was to reduce maternal mortality and morbidity due to illegal, unsafe abortion by making safe abortion service available to all women in the country. ${ }^{3}$ In India, the Medical Termination of Pregnancy Act (MTP Act) was approved by Parliament in 1971 and came into force from 2nd April 1972. Rules were amended in 2003 to strengthen the MTP Act. ${ }^{3}$ In India, MTP Act, 1971 allows termination of pregnancy up to 20 weeks of gestation under specified conditions. However, the opinion of two registered medical 
practitioners (RMP's) is required to terminate a second trimester pregnancy. ${ }^{4}$

Mid-trimester termination of pregnancy has to be done when the woman delays in seeking advice, due to ignorance, psychological factors, socio-cultural problem, late identification of medical disorders and fetal abnormalities. It was also proposed that pre-treatment with mifepristone would improve the performance of misoprostol. Mifepristone primary role in second trimester abortion is to prepare the cervix, to sensitize the uterus to prostaglandins and thus making administration of misoprostol more effective. Misoprostol serves to dilate the cervix and induce uterine contraction. ${ }^{5}$ WHO recommend the combined use of Mifepristone and Misoprostol as the safest and most effective schema of mid- trimester pregnancy termination. ${ }^{6}$

\section{METHODS}

This institution based contingent study was conducted on 220 women attending in the Department of Obstetrics and Gynaecology, Zanana Hospital, SMS Medical College, Jaipur for second-trimester termination of pregnancy between 12-20 weeks of gestational age during 2012-13 after approval by the ethical committee of the institute. After satisfying inclusion and exclusion criteria, women were selected using computer based random allocation method in 2 groups, each group comprising 110 women, after proper counselling and informed written consent of the women.

Group A: Women received $200 \mathrm{mg}$ oral mifepristone followed by sublingual misoprostrol $400 \mu \mathrm{g}$ every three hours for a maximum of five doses 48 hours later.
Group B: Women received $200 \mathrm{mg}$ oral mifepristone followed by oral misoprostrol $400 \mu \mathrm{g}$ every three hours for a maximum of five doses $48 \mathrm{hrs}$ later.

The sequel of misoprostol was repeated if the woman fails to abort within $24 \mathrm{hrs}$ of misoprostol. The inductionabortion interval was defined as the period between the time of administration of the first dose of misoprostol to the duration when the fetus aborted. Fruitful abortion was defined as abortion occurring within $24 \mathrm{hrs}$ without the need for further prostaglandins or oxytocin.

\section{Statistical analysis}

The data were analyzed using computer statistical software (Microsoft Excel, SPSS 20 and primer). Descriptive statistics (mean, standard deviation and proportions) were used to summarize the study variables. ANOVA test for independent samples was used to compare the mean values of continuous study variables.

Paired T Test was used for the data compared before and after the abortion. The $95 \%$ confidence intervals for difference of mean were used. Chi-square test was used to observe an association between the qualitative study and outcome variables. A p-value of less than 0.05 was considered statistically significant.

\section{RESULTS}

In present study induction-abortion interval of Group-A and Group B was $4.02 \pm 1.39$ hours and $6.44 \pm 1.79 \mathrm{hrs}$. Induction-abortion interval of Group-A was significantly shorter than Group-B $(\mathrm{P}=0.001)$ (Table 1).

Table 1: Distribution of cases according to mean induction-abortion interval in both groups.

\begin{tabular}{|c|c|c|c|c|c|c|}
\hline \multirow{2}{*}{ Mean induction-abortion interval (in hours) } & \multicolumn{2}{|c|}{ Group-A } & \multicolumn{2}{|c|}{ Group-B } & \multicolumn{2}{|c|}{ Total } \\
\hline & No. & $\%$ & No. & $\%$ & No. & $\%$ \\
\hline$\leq 4$ & 79 & 71.80 & 11 & 10.00 & 90 & 40.91 \\
\hline $5-8$ & 30 & 27.30 & 87 & 79.10 & 117 & 53.18 \\
\hline $9-12$ & 0 & 0.00 & 11 & 10.00 & 11 & 5.00 \\
\hline $13-16$ & 1 & 0.90 & 1 & 0.90 & 2 & 0.91 \\
\hline $17-20$ & 0 & 0.00 & 0 & 0.00 & 0 & 0.00 \\
\hline $21-24$ & 0 & 0.00 & 0 & 0.00 & 0 & 0.00 \\
\hline Total & 110 & 100.00 & 110 & 100.00 & 220 & 100.00 \\
\hline
\end{tabular}

$\mathrm{X}^{2}=90.147$, d.f. $=3, \mathrm{P}=0.001$, HS; Mean $\pm \mathrm{SD}($ Group$-\mathrm{A})=4.02 \pm 1.39$ hours; Mean $\pm \mathrm{SD}($ Group$-\mathrm{B})=6.44 \pm 1.79$ hours

Overall $62 \%$ cases had achieved successful abortion with two doses of Misoprostol. The mean dose of Misoprostol in Group-A and Group- B was $680 \pm 220.4 \mu \mathrm{g}$ and $1003.6 \pm 274.9 \mu \mathrm{g}$ respectively. Fewer doses were required among Group-A (sublingual group) as compared to Group-B (oral group) and this difference was statistically significant.
In Group-A $32.73 \%$ of women get aborted with $1^{\text {st }}$ dose of Misoprostol and $64.54 \%$ women got aborted with 2nd dose of Misoprostol. In Group-B 3.64\% of women got aborted with 1 st dose of Misoprostol, $48.18 \%$ of women got aborted with 2nd dose of Misoprostol and remaining women required 3 or more doses of Misoprostol (Table 2). 
There was insignificant difference in the need for evacuation in both the groups. Evacuation was done in 4
(3.64\%) women in Group-B as compare to only 1 $(0.91 \%)$ in Group-A (Table 3).

Table 2: Distribution of cases according to dose of misoprostol required in both the groups.

\begin{tabular}{|l|l|l|l|l|l|l|}
\hline \multirow{2}{*}{ Dose of Misoprostol (in $\mu \mathrm{gg})$} & Group-A & Group-B & Total & \% \\
\hline 1 & No. & \% & No. & \% & No. & 18.18 \\
\hline 2 & 36 & 32.73 & 4 & 3.64 & 40 & 56.36 \\
\hline 3 & 71 & 64.54 & 53 & 48.18 & 124 & 22.27 \\
\hline 4 & 2 & 1.82 & 47 & 42.73 & 49 & 2.73 \\
\hline 5 & 1 & 0.91 & 5 & 4.54 & 6 & 0.46 \\
\hline Total & 0 & 0.00 & 1 & 0.91 & 1 & 100.00 \\
\hline
\end{tabular}

$\chi 2=73.2$, d.f. $=4, \mathrm{P}=0.001, \mathrm{HS} ;$ Mean $\pm \mathrm{SD}($ Group$-\mathrm{A})=680 \pm 220.4 \mu \mathrm{g} ;$ Mean $\pm \mathrm{SD}($ Group-B $)=1003.6 \pm 274.9 \mu \mathrm{g}$

Table 3: Distribution of cases according to need for evacuation.

\begin{tabular}{|l|l|l|l|l|}
\hline \multirow{2}{*}{ Need for evacuation } & \multicolumn{2}{c}{ Group-A } & \multicolumn{2}{c|}{ Group-B } \\
\cline { 2 - 5 } & No. & $\mathbf{\%}$ & No. & \% \\
\hline Required & 1 & 0.91 & 4 & 3.64 \\
\hline Not required & 109 & 99.09 & 106 & 96.36 \\
\hline Total & 110 & 100.00 & 110 & 100.00 \\
\hline
\end{tabular}

$\mathrm{X}^{2}=0.819$, d.f. $=1, \mathrm{P}=0.3$, NS

In present study acceptability were significantly higher in Group-B (100\%) as compared to Group-A (52.73\%), probably because of unpleasant taste of sublingual Misoprostol (Table 4).

Table 4: Distribution of cases according to acceptability.

\begin{tabular}{|l|l|l|l|l|}
\hline \multirow{2}{*}{ Acceptability } & \multicolumn{2}{c}{ Group-A } & \multicolumn{2}{c|}{ Group-B } \\
\hline No. & \% & No. & $\%$ \\
\hline Accepted & 58 & 52.73 & 100 & 100.00 \\
\hline Not Accepted & 52 & 47.27 & 0 & 0.00 \\
\hline Total & 110 & 100.00 & 110 & 100.00 \\
\hline$\chi 2=60.319$, d.f. $=1$, P $<0.001$, HS & & \\
\hline
\end{tabular}

Commonest side-effects in both the groups were nausea/vomiting (34.5\% in both groups) followed by pain $(26.40 \%, 34.50 \%)$, headache $(14.5 \%, 17.3 \%)$ and diarrhoea $(12.7 \%, 17.3 \%)$ which was not statistically significant ( $\mathrm{p}$ value $>0.05$ ).

However, fever was seen in $12.7 \%$ women in Group-A and $0.9 \%$ women in Group-B and P-value is 0.001, which was statistically significant.

For these side effects, symptomatic treatment was given (Table-5).
Table 5: Distribution of cases according to side-effects in whole group.

\begin{tabular}{|c|c|c|c|c|c|}
\hline \multirow{2}{*}{ Side effects } & \multicolumn{2}{|c|}{ Group-A } & \multicolumn{2}{|c|}{ Group-B } & \multirow{2}{*}{$\begin{array}{l}\text { Chi- } \\
\text { square } \\
\text { test }\end{array}$} \\
\hline & No. & $\%$ & No. & $\%$ & \\
\hline Pain & 29 & 26.40 & 38 & 34.50 & $\begin{array}{l}\chi^{2}=1.374, \\
\text { d.f. }=1, \\
P=0.2, \mathrm{NS}\end{array}$ \\
\hline $\begin{array}{l}\text { Nausea/ } \\
\text { Vomiting }\end{array}$ & 38 & 34.50 & 38 & 34.50 & $\begin{array}{l}\chi^{2}=0.020, \\
\text { d.f. }=1, \\
P=0.8, N S\end{array}$ \\
\hline Headache & 16 & 14.50 & 19 & 17.30 & $\begin{array}{l}\chi^{2}=0.136, \\
\text { d.f. }=1, \\
P=0.7, \mathrm{NS}\end{array}$ \\
\hline Diarrhoea & 14 & 12.70 & 19 & 17.30 & $\begin{array}{l}\chi^{2}=0.570, \\
\text { d.f. }=1, \\
P=0.4, N S\end{array}$ \\
\hline Fever & 14 & 12.70 & 1 & 0.90 & $\begin{array}{l}\chi^{2}=10.30, \\
\text { d.f. }=1, \\
P=0.00, \\
\text { HS }\end{array}$ \\
\hline
\end{tabular}

\section{DISCUSSION}

The results were consonant with study done by Ngai et al where mean induction-abortion interval was 10.0 hours in Group-A and 10.4 hours Group-B respectively. ${ }^{7}$ The results of present study were comparable to study done by Tang OS et al who found that mean induction-abortion interval was significantly less $(\mathrm{P}=0.009)$ in the sublingual group (5.5 hours) as compared to oral group (7.5 hours). ${ }^{5}$ In a similar study conducted by Devendra Kushwaha et al who found the mean \pm SD induction to evacuation interval in the sublingual group and oral groups were 5.6 \pm 4.54 hours and $9.44 \pm 5.61$ hours respectively. ${ }^{8}$ 
In a similar study by Ngai et al average dose of Misoprostol in Group-A and Group-B was $600 \mu \mathrm{g}$ and $1200 \mu \mathrm{g}$ respectively $(\mathrm{P}<0.05) .^{7}$ The results of present study were comparable to Caliskan $\mathrm{E}$ et al who found total dose of Misoprostol was $543 \pm 422 \mu \mathrm{g}$ in the sublingual group, $878 \pm 533 \mu \mathrm{g}$ in the vaginal group and $741 \pm 413 \mu \mathrm{g}$ in the oral group $(\mathrm{P}<0.001){ }^{9}$ The results of present study were comparable to study done by Devendra Kushwaha et al who found the number of cases aborted with 1 dose of Misoprostol was higher in the sublingual group $(86 \%)$ as compared to oral group $(\mathrm{P}=0.004) .{ }^{8}$ However, Ngai et al found need of curettage in study and control group was $24.6 \%$ and $18.6 \%$ respectively. ${ }^{7}$ The results were comparable with study done by Tang OS et al who found that $10(17.2 \%)$ and 7 $(11.7 \%)$ subjects in the sublingual and oral groups respectively required surgical evacuation for incomplete abortion. $^{5}$ The difference was not significant statistically(P-value $>0.05)$. In a study done by Suk Wai Nagai et al concluded that $82 \%$ of women preferred oral route. ${ }^{7}$ In a similar study done by Shah $\mathrm{N}$ et al, the incidence of unpleasant taste was significantly higher in the sublingual group than in the vaginal group $(60 \%$ vs $4 \%, \mathrm{P} \pm 0.001)^{10}$

The results were also comparable to study done by Cabrera $\mathrm{Y}$ et al who found the sublingual route shortened the induction-fetal expulsion interval $(4.54,95 \% \mathrm{CI}-8.03$ to -1.05$)$ and was the route preferred among women. ${ }^{11}$ In a study conducted by Devendra Singh Kushwaha et al concluded that sublingual route of administration was more acceptable than the oral route $\left(\mathrm{X}^{2}=6.78, \mathrm{P}=0.009\right.$, d.f. $=6) .{ }^{8}$ However different observations were made by Suk Wai Nagai et al concluded that for the oral group, both the incidence of diarrhoea $(40.0 \% \mathrm{v} / \mathrm{s} 23.2 \%)$ and amount of drug used (1734 compared with $812 \mu \mathrm{g}, \mathrm{P}<$ $0.0001)$ were significantly higher than vaginal group but the incidence of fever appeared to be lower. ${ }^{7}$ The results were also consonant to study done by Tang OS et al who found that incidence of fever was higher in the sublingual group $(\mathrm{P}<0.0001)$. The incidence of other side-effects were similar. ${ }^{5}$

No significant difference in the side-effect were noted in the study conducted by Devendra Singh Kushwaha et al (2011)8 concluded that $17(34 \%)$ cases in sublingual group and $26(52 \%)$ cases in oral group had nausea $(\mathrm{P}=$ $0.3031)$, whereas $24(48 \%)$ cases in sublingual group and $28(86 \%)$ cases in oral group had diarrhoea $(\mathrm{P}>0.05)$.

\section{CONCLUSION}

Over the past twenty years, use of medications for midtrimester termination of pregnancy become safer, developed and more reachable. Today in most cases, safe and competent medical abortion services can be provided or improved by few changes in existing health care facilities. Mid-trimester desistance of pregnancy using combination of Mifepristone and Misoprostol is a secure, non-invasive, highly cost-effective method with a high accomplishment rate and short induction-abortion interval. Pretreatment with Mifepristone adds to the effectiveness of the Misoprostol as an abortifacient.

WHO recommend the combined use of Mifepristone and Misoprostol as the secure and most competent method of mid- trimester pregnancy termination.

In present study authors studied the use of sublingual Misoprostol for medical abortion in mid- trimester (12-20 weeks). From present study authors conclude that, sublingual Misoprostol when combined with Mifepristone is effective for medical abortion in second trimester in terms of efficacy, tolerability and success rate than the oral route.

\section{Funding: No funding sources}

Conflict of interest: None declared

Ethical approval: The study was approved by the Institutional Ethics Committee

\section{REFERENCES}

1. Katz VL, Lentz GM. Congenital abnormalities of the female reproductive tract. Comprehens Gynecol. 2012:187.

2. Shah I, Åhman E. Unsafe abortion: global and regional incidence, trends, consequences, and challenges. J Obstet Gynaecol Canada. 2009;31(12):1149-58.

3. Medical Termination of Pregnancy, Regulation 2003. Ministry of Health and Family Welfare (Deptt of Family Planning), New Delhi, 2003.

4. Gemzell-Danielsson K, Lalitkumar S. Second trimester medical abortion with mifepristonemisoprostol and misoprostol alone: a review of methods and management. Reprod Health Matters. 2008;16(sup31):162-72.

5. Tang OS, Chan CC, Kan AS, Ho PC. A prospective randomized comparison of sublingual and oral misoprostol when combined with mifepristone for medical abortion at 12-20 weeks gestation. Hum Reprod. 2005;20(11):3062-6.

6. Trainer Manual of Comprehensive Abortion Care, 2009. Method of second trimester termination, pg 233.

7. Ngai SW, Tang OS, Ho PC. Randomized comparison of vaginal $(200 \mu \mathrm{g}$ every $3 \mathrm{~h})$ and oral (400 $\mu \mathrm{g}$ every $3 \mathrm{~h}$ ) misoprostol when combined with mifepristone in termination of second trimester pregnancy. Hum Reprod. 2000;15(10):2205-8.

8. Kushwah DS, Kushwah B, Salman MT, Verma VK. Acceptability and safety profile of oral and sublingual misoprostol for uterine evacuation following early fetal demise. Indian $\mathrm{J}$ Pharmacol. 2011;43(3):306-10.

9. Caliskan E, Dilbaz S, Doger E, Ozeren S, Dilbaz B. Randomized comparison of 3 misoprostol protocols for abortion induction at 13-20 weeks of gestation. J Reprod Med. 2005;50(3):173-80. 
10. Shah N, Azam SI, Khan NH. Sublingual versus vaginal misoprostol in the management of missed miscarriage. J Pak Med Assoc. 2010;60(2):113-6.

11. Cabrera Y, Fernández-Guisasola J, Lobo P, Gámir S, Alvarez J. Comparison of sublingual versus vaginal misoprostol for second-trimester pregnancy termination: a meta-analysis. Aust NZJ Obstet Gynaecol. 2011;51(2):158-65.
Cite this article as: Gupta R, Banerjee KP, Pant R. A comparative study of sublingual versus oral misoprostol following oral mifepristone for second trimester termination of pregnancy. Int J Reprod Contracept Obstet Gynecol 2019;8:498-502. 